\title{
PERCEPÇÕES DA SEMANA dO CALOURO NA COMPREENSÃO DA APRENDIZAGEM BASEADA EM PROBLEMAS: UMA ANÁLISE INTER PARES
}

\section{ARTIGO ORIGINAL}

CHAGAS, Jéssica Andréa Silva das ${ }^{1}$

RUSSO, Marina Rodrigues ${ }^{2}$

ALVES, Weksiley Sousa ${ }^{3}$

FECURY, Amanda Alves ${ }^{4}$

CHAGAS, Jéssica Andréa Silva das. Et al. Percepções da semana do calouro na compreensão da aprendizagem baseada em problemas: Uma análise inter pares. Revista Científica Multidisciplinar Núcleo do Conhecimento. Ano 06, Ed. 01, Vol. 07, pp. 17-35. Janeiro de 2021. ISSN: 2448-0959, Link de acesso: https://www.nucleodoconhecimento.com.br/saude/semana-do-calouro

\section{RESUMO}

Introdução: O método PBL (Aprendizagem Baseada em Problemas) desenvolveu-se com base nas características de aprendizado do adulto, e fornece mais autonomia aos estudantes. A Semana do Calouro (SECA) objetiva introduzir o estudante ao ambiente acadêmico e ao método de ensino. Objetivo: Acadêmicos veteranos avaliarem a efetividade das atividades realizadas na SECA, relacionadas à introdução ao PBL, a partir das experiências dos calouros da graduação de Medicina da

${ }^{1}$ Discente do $6^{\circ}$ ano do curso de medicina da Universidade Federal do Amapá.

${ }^{2}$ Discente do $5^{\circ}$ ano do curso de medicina da Universidade Federal do Amapá.

${ }^{3}$ Discente do $5^{\circ}$ ano do curso de medicina da Universidade Federal do Amapá.

${ }^{4}$ Orientadora. Doutorado em Doenças Tropicais. Mestrado em Doenças Tropicais. Especialização em Especialização em Microbiologia. Graduação em Biomedicina. 
Universidade Federal do Amapá (UNIFAP). Métodos: Foi realizada pesquisa transversal, qualitativa, através de dois grupos focais, cujos participantes foram alunos dos $1^{\circ}$ semestres de 2016 e 2017. Os temas mais abordados foram: manual do calouro, tutorial-simulado, método PBL e semana do calouro. As sessões foram registradas e seu conteúdo analisado utilizando a plataforma Wordle.net, segundo a técnica de Bardin adaptada. Resultados: O tutorial-simulado e o manual do calouro foram tidos como positivos pelos acadêmicos. A simulação possibilitou entendimento de um tutorial real e o manual forneceu informações relevantes sobre o curso e o método. Houve críticas e sugestões: incompatibilidade do calendário acadêmico com a SECA e adição de informações ao manual. Conclusões: As estratégias utilizadas tiveram ampla aceitação e foram úteis para os alunos, devendo ser mantidas e aprimoradas para as próximas turmas.

Palavras-chave: Grupo Focal, PBL, Semana do Calouro.

\section{INTRODUÇÃO}

O desenvolvimento da educação foi fundamentado inicialmente em um modelo pedagógico tradicional-conservador, fundamentado no papel central do professor como dono do conhecimento e do aluno como um ser passivo, sendo o conhecimento repassado normalmente através de aulas teórico-expositivas (SANTOS, 2011; RODRIGUES et al., 2013). Tal método, no entanto, dificulta que o indivíduo pense na aplicabilidade da teoria exposta em sala de aula, tornando-se necessário fomentar a busca por práticas pedagógicas inovadoras, que garantam a aquisição de capacidades e atitudes tanto quanto do conhecimento (WEINTRAUB; HAWLITSCHEK; JOÃO, 2011).

No contexto de transformação dos modelos educacionais, fortaleceram-se as metodologias ativas em substituição aos métodos tradicionais. Nesse contexto, a Aprendizagem Baseada em Problemas (APB ou PBL- do inglês Problem Based Learning) baseia-se no papel do aluno como sujeito ativo, no sentido de que o mesmo aprende de maneira autônoma e colaborativa, constrói e reconstrói seu conhecimento, deixando de ser um elemento passivo, exposto à informação por meio de aulas e 
passando a buscar o conhecimento para resolução de problemas mediados pelas atividades recorrentes do método e pelas novas funções que tanto alunos quanto tutores precisam exercer (DE CAMPOS, 2014). Essa abordagem é inovadora e muito positiva para o processo ensino-aprendizagem por que a participação ativa dos discentes na construção do conhecimento é essencial para o aprendizado, memorização de conteúdos e desenvolvimento de habilidades que são imprescindíveis para a construção do bom profissional médico (TOLEDO JÚNIOR et al., 2008).

Considerando que os métodos ativos são aplicados sobretudo no ensino superior e que a educação básica no Brasil continua centrada em metodologias tradicionais, o aluno ingresso na graduação tende a sofrer com dificuldades que englobam problemas estruturais, organizacionais e com os docentes, fato esses decorrentes da mudança repentina de metodologia (FERNANDES; MELLO; MELLO, 2001). Desde sua implantação na Escola de Medicina da Universidade McMaster o PBL tem sido adaptado a muitos contextos educacionais e ao ensino de diversas áreas do conhecimento. Hoje é possível encontrar implantações do PBL em áreas tão distintas quanto a história, pedagogia arquitetura e a engenharia, na qual acontece há muito tempo e está bem documentado na literatura (DE CAMARGO RIBEIRO, 2008).

O método tem sido bastante aplicado em diversas escolas no mundo inteiro e, no Brasil, vê-se seu desenvolvimento nas várias experiências de mudança curricular nos cursos da área da saúde, sobretudo de medicina (MAMEDE et al., 2001; FRANCO; CUBAS; FRANCO, 2014). Seguindo tais parâmetros, o curso de medicina da Universidade Federal do Amapá foi implantado já aderindo à metodologia PBL.

O modo como os alunos se integram ao contexto do ensino superior faz com que eles possam aproveitar melhor (ou não) as oportunidades oferecidas pela universidade, em âmbitos profissional e psicossocial. Aqueles que se integram acadêmica e socialmente desde o início de seus cursos têm possivelmente mais chances de crescerem intelectual e pessoalmente do que aqueles que enfrentam mais dificuldades na transição à universidade (TEIXEIRA et al., 2008). A Semana de Recepção ao Calouro é um momento de conhecimento dos espaços universitários e 
de entrosamento através de atividades culturais, sociais, acadêmicas, e busca portanto diminuir o impacto do novo e estranho ambiente físico e social (BELLODI, 2004). Deve cumprir a sua função de recepção acadêmica e de apresentação da metodologia vigente. A partir disto, é possível então reconhecer a relevância desse trabalho, que visou avaliar tais funções e obter através dos resultados subsídios para melhorar a percepção e instrução do aluno na metodologia ativa.

O interesse de inovação pedagógica também se situa no aspecto do treinamento e posterior avaliação inter pares entre veteranos e calouros. Onde veteranos planejaram e executaram os grupos focais para os calouros participarem, com o objetivo de analisar as percepções da influência da SECA na compreensão da metodologia PBL, escolhida por ser a utilizada no curso de medicina da UNIFAP. Os grupos focais contêm procedimentos que visam o entendimento das experiências do grupo e do seu ponto de vista (IERVOLINO; PELICIONI, 2001).

Além disso, todas as estratégias avaliadas no presente trabalho mostram-se alternativas à cultura de trotes tradicionais violentos, sendo essa substituição o início da vida acadêmica em sua faceta crítica e meditativa, além de condição fundamental para a própria defesa da universidade como espaço da democracia, do humanismo e da cultura (VASCONCELOS, 1993).

\section{METODOLOGIA}

\subsection{DELINEAMENTO DO ESTUDO E ASPECTOS ÉTICOS}

Trata-se de uma pesquisa qualitativa desenvolvida entre estudantes do Curso de Medicina da Universidade Federal do Amapá (UNIFAP), sob supervisão de professores do colegiado. A coleta de dados ocorreu nos primeiros semestres dos anos letivos 2016 e 2017. O estudo obedeceu aos critérios de Ética e Pesquisa com seres humanos, conforme Resolução n‥ 466/2012 do Conselho Nacional de Saúde, sendo aprovado pelo Comitê de Ética em Pesquisa (CAAE no 1.841 .717 ). 


\subsection{PARTICIPANTES E CRITÉRIOS DE INCLUSÃO E EXCLUSÃO}

A amostra foi composta por dois grupos, sendo um constituído por 7 discentes da turma do $1^{\circ}$ semestre de 2016 e outro com 8 acadêmicos da turma do $1^{\circ}$ semestre de 2017, totalizando 15 alunos e sendo os respectivos grupos denominados grupos A e B. Foram critérios de inclusão: ser aluno regularmente matriculado no primeiro semestre, de ambos os sexos, maiores de 18 anos, com condições físicas, mentais e intelectuais para comunicar-se com os pesquisadores e que aceitarem participar do estudo; e de exclusão: quaisquer acadêmicos que não estejam ingressando no $1^{\circ}$ ano, ou que no período do estudo estejam ausentes por motivo de viagem, trabalho, passeio, internação ou tratamento e aqueles que não aceitarem participar do estudo.

\subsection{PROCEDIMENTO}

Foi empregada a técnica grupo focal - caracterizada pela integração de pessoas, que permite debate vasto e argumentação sobre determinado assunto (BELFOR et al., 2018) para conhecer a percepção dos estudantes acerca da Semana do Calouro (SECA). Foram realizados dois grupos focais, que ocorreram no prédio do curso de Medicina da UNIFAP em dias diferentes, um com cada turma de alunos do $1^{\circ}$ ano que aceitaram participar, após assinatura de um Termo de Consentimento Livre e Esclarecido (TCLE) e de Termo de Cessão de Direitos para o Uso de Imagem e Som.

Analisou-se através dos grupos focais a visão dos acadêmicos em relação, entre outros aspectos, às estratégias utilizadas na SECA para facilitar a adaptação dos mesmos, conforme roteiro previamente estabelecido. Sendo elas:

a) O tutorial simulado: constitui-se de uma sessão simulada de tutorial realizada com as novas turmas antes de começarem as aulas e os tutoriais verdadeiros, que teve duração de 1 hora, com um total de 15 acadêmicos participantes, sendo 12 calouros e 3 veteranos. Os próprios veteranos escreveram e conduziram a situação problema, que tinha o tema ENEM (Exame Nacional do Ensino Médio). As funções de coordenador, secretário e tutor foram também desempenhadas pelos veteranos, uma 
vez que nesse primeiro momento os calouros não possuíam familiaridade nenhuma com as mesmas.

b) O Manual do Calouro: é uma compilação de informações sobre a estrutura do curso, da universidade, sobre a metodologia PBL e sobre a cidade de Macapá. Se utilizando de linguagem simples e informal, este impresso orienta os acadêmicos. Dentre os assuntos abordados tem-se: como funciona e as formas de avaliação do PBL; bolsas e auxílios na UNIFAP; itens essenciais para começar o ano; serviços oferecidos pela universidade (restaurante universitário e serviço de apoio psicológico, por exemplo); telefones e locais úteis na cidade (para calouros egressos de outros estados); Funções das Pró-reitorias e o mapa da Universidade. Além de destes, a turma responsável por realizar a SECA dos ingressantes em 2017 acrescentou um fluxograma de abertura de tutorial.

c) A estratégia de apadrinhamento: que consiste em cada novo aluno ser orientado por um veterano (padrinho/madrinha) de acordo com as necessidades do calouro e experiências adquiridas pelos padrinhos, pois o mundo universitário é menos estruturado que o escolar, havendo a necessidade de estabelecer novos vínculos de amizade (TEIXEIRA et al., 2008). As trocas de experiência podem ser relacionadas aos estudos (orientações a respeito dos professores, disciplinas e hábitos, trocas de material), à universidade e também à adaptação na cidade.

Ambos os grupos focais iniciaram com a apresentação do moderador, do observador e dos participantes. Os moderadores e observadores, assim como a equipe de registro e filmagem, constituíram-se de 4 acadêmicos veteranos, sob supervisão de 2 docentes.

Foi explanada a finalidade da reunião e os objetivos da pesquisa. Em consonância com a metodologia, houve discurso para motivar os sujeitos da pesquisa, garantindose o anonimato da entrevista e o sigilo da autoria das respostas. 


\subsection{INSTRUMENTO DE COLETA DE DADOS}

Foram realizadas no grupo focal perguntas estruturadas em 3 categorias, conforme roteiro: pergunta de abertura ("Qual sua percepção sobre esta etapa da SECA?" referindo-se à apresentação do PBL), perguntas de desenvolvimento do assunto abordado (Depois do tutorial simulado, vocês conseguiram entender mais sobre como funciona um tutorial real? Conseguiriam explicar tal funcionamento para uma pessoa leiga? Ao saírem da simulação, se sentiram preparados para começar o semestre? Qual sua opinião sobre a estratégia "Manual do Calouro"? e perguntas finalizadoras ("Em sua opinião, quais são os aspectos negativos dessa etapa da SECA? E os positivos? Se forem repetir essas atividades com os próximos calouros, irão mudar alguma coisa? Se sim, o que?).

\subsection{ANÁLISE DE DADOS}

Após gravação, os relatos reunidos nos encontros de grupo focal foram transcritos e analisados em dois passos: primeiro os discursos foram aplicados na plataforma Wordle.net para identificar as palavras mais proferidas e depois realizou-se análise de conteúdo e identificação dos temas mais emergentes com a técnica de Bardin (2009) adaptada.

Conforme o desenho metodológico desta pesquisa, após a identificação das palavraschave obtidas na discussão, as frases nas quais as mesmas estavam inseridas foram selecionadas e categorizadas em domínios temáticos para facilitar a interpretação do conteúdo e posterior comparação com a literatura. Os discursos foram analisados tanto individualmente quanto comparativamente entre os dois grupos.

\section{RESULTADOS E DISCUSSÃO}

No grupo A, as palavras mais frequentes foram: "tutorial", "manual (do calouro)", "tutorial simulado", "calouro", "PBL", "semana do calouro" e "trote". Já as mais faladas no grupo B foram: "calouro", "semana", "PBL", "tutorial simulado", "veterano", "manual (do calouro)" e "aluno". A partir da análise das frases nas quais estas palavras estavam 
inseridas, pôde-se fazer a seguinte categorização de temas: Efetividade do tutorial simulado e inseguranças com a nova metodologia, Utilidades e importância do Manual do Calouro, Acolhimento satisfatório e Considerações gerais: Críticas e sugestões.

\subsection{EFETIVIDADE DO TUTORIAL SIMULADO E INSEGURANÇAS COM A NOVA METODOLOGIA}

Com relação à avaliação do tutorial simulado, em ambos os grupos se enfatizou a questão de o tutorial só ser aprendido em todas as suas nuances com o tempo e prática, pois além de adquirir-se desenvoltura também se conhece os tutores e suas diversas formas de avaliar, bem como os temas discutidos. Ressaltou-se a importância da simulação de uma sessão de tutoria como uma primeira ideia do assunto, o início do exercício antes de os alunos começarem os tutoriais de fato, mas que a prática ainda é soberana. Os calouros também assimilam através dos outros alunos que o curso melhora com o tempo. Para tal, é preciso desenvolver resiliência acadêmica, sendo o ambiente escolar é propício para desenvolver esta qualidade, uma vez que é um local em que há necessidade de resolução de conflitos e amparo educacional adequado (GARCIA, 2001; BRASIL, 2019).

Eu acho que mesmo depois da simulação, a gente soube de verdade o que era depois que a gente começou a participar. Porque esse foi mais como uma brincadeira e tal. Tipo, ajudou? Ajudou, mas acho que a gente só começou a ver e tal (...). (Acadêmica do grupo B).

Entre os pontos positivos relatados nos grupos A e B sobre a simulação, pode-se salientar que foi considerada de grande auxílio para os acadêmicos, funcionando como um embasamento, onde se pôde conhecer a estrutura do mesmo, as regras básicas que o regem, os papéis do coordenador, secretário, tutor e dos outros membros do grupo tutorial, além de poder conhecer a ordem em que abertura e fechamento são conduzidos. Azer (2005, p.676), em seu trabalho sobre PBL, cita algumas dessas regras: desligar os celulares, respeitar as diferentes opiniões e pontos de vista, ouvir os participantes com atenção e contribuir com a discussão. 
Os acadêmicos também mencionaram que essa experiência lhes proporcionou mais segurança e que o fato de a sessão simulada ter sido pela manhã e o tutorial "verdadeiro" à tarde os ajudou a se prepararem. Mesmo aqueles que não puderam estar presentes na simulação ouviram os comentários positivos a respeito e puderam receber as informações através de seus colegas:

Esclareceu muita coisa por que... pelo menos eu não fazia a mínima ideia, como vocês haviam dito anteriormente... A gente vem de um ensino tradicional e acho que grande parte da turma nem imaginava o que era uma sessão de tutorial. E esclareceu, tirou o medo que a gente tinha também, a gente pensava que era uma coisa bem mais... não que não seja sério, mas a gente achou que seria uma coisa bem mais metódica, e enfim... foi muito bom pra que nos preparássemos pra quando nós o fizéssemos de fato. (Acadêmico do grupo B).

Relataram, nos dois grupos, que mesmo com a realização da simulação, ainda persistiram dificuldades e inseguranças, principalmente relacionadas a adaptação com o novo método. Enquanto alguns alunos veem as adversidades como invencíveis, outros as percebem como obstáculos a serem ultrapassados e conseguem enfrentá-las. (ZAJACOVA; LYNCH; ESPENSHADE, 2005).

Então a gente teve que mudar e ai, como, isso meio que já quebrou a segurança que eu tinha, por que eu já estava com um grupo, e aí, eu me lembro que a gente estava tão inseguro, que a gente fez um... Se reuniu pra combinar o que era pra falar antes do tutorial. (Acadêmica do grupo $A$, sobre um momento em que precisou mudar de grupo, em uma situação imprevista).

Essas inseguranças são compreensíveis e explicadas pela mudança drástica de metodologia, porém alguns autores relatam que o PBL pode aumentar as motivações dos alunos, tendo um papel no desenvolvimento de autonomia e de relacionamentos (RYAN; DECI, 2000; DECI; RYAN, 2002; TEN CATE; KUSURKAR; WILLIAMS, 2011). As habilidades sociais são um componente chave da teoria da interdependência social, um das perspectivas teóricas de aprendizagem grupal em PBL (TORRE; VAN DER VLEUTEN; DOLMANS, 2015).

Apesar da boa aceitação, quando perguntados se a simulação os capacitaria para explicar pra uma pessoa leiga como funciona um tutorial, a maioria dos alunos de 
ambos os grupos respondeu que apenas isso não seria suficiente para fazê-los entender e reproduzir as informações, que alguns aspectos poderiam ser expostos, mas que não seria uma explicação completa e completamente eficiente.

Dois alunos do grupo A relataram a observação prévia de um tutorial como fator esclarecedor: “(...) Eu fiquei um tempão em Fortaleza, e lá eu pude assistir, o tutorial, então tive mais ou menos uma ideia." (Acadêmica do grupo A).

Com relação à vivência dos tutoriais na rotina acadêmica após a SECA, alunos do grupo B enfatizaram que ainda não se sentiam totalmente preparados. Descreveram, por exemplo, que não sabiam fazer o mapa conceitual no quadro, tarefa avaliativa muito importante do secretário. É papel do secretário escutar as contribuições de cada membro, registrar e organizar as informações discutidas, além de estimular cada um a contribuir e buscar conhecer como servir o grupo. O uso de mapas, diagramas e fluxogramas no quadro deve ser encorajado, isso permite que todos os membros do grupo vejam e participem, facilitando esclarecimentos (AZER, 2005; TORRE; VAN DER VLEUTEN; DOLMANS, 2015). “Um mapa conceitual é uma representação gráfica de conhecimento em que os conceitos são relacionados através da ligação palavras para criar significado" (NOVAK; GOWIN, 1984).

Além disso, relataram que ainda não sabiam exatamente como estudar da maneira correta para um tutorial: “(...), Mas PBL a gente não sabe estudar até hoje, não sabe mesmo! Chega no tutorial, a gente não sabe estudar!" (Acadêmica do grupo B). Declaração esta que necessita atenção, uma vez que de acordo com Torre et al. (2015, p.6) "a fase de auto estudo é um passo crucial no PBL" e o autoaprendizado é um passo originado da atividade grupal cuja função é reportar ao grupo, por isso está intrinsicamente ligado ao aprendizado em grupo, interdependência social, criação de conhecimento e obtenção de objetivos em comum.

\subsection{UTILIDADES E IMPORTÂNCIA DO MANUAL DO CALOURO}

O manual do calouro se destacou como ferramenta utilizada para conhecer o curso e

o novo método, tendo elevada aceitação em ambos os grupos. Além de ser um 
proposta interessante do ponto de vista acadêmico, considerando que aproximadamente $60 \%$ dos acadêmicos de medicina da UNIFAP são de outras cidades (DE OLIVEIRA et al., 2017), foi considerado pelos alunos um gesto de preocupação e empatia por parte de seus veteranos, uma vez que a saída da casa dos pais é um processo complexo e um marco importante (WAGNER, 2014). Os estudantes avaliaram o manual como "muito bom" e disseram que forneceu importante embasamento para iniciar o curso, desde situações mínimas como objetos necessários no cotidiano de um calouro, até informações importantes como o que significa cada eixo temático do PBL.

Assim, o que eu aprendi muito no manual foi o que cada matéria significava, como não era matéria, como é a organização do módulo, acho que tava escrito isso... essas coisas... e esquema de nota assim... que vocês falando, eu não consegui entender, mas quando eu li meio que peguei mais ou menos, tanto que depois eu peguei pra ler de volta. (Acadêmico do grupo A).

Uma acadêmica do grupo B reiterou: "Eles tinham pensado assim mesmo na gente, pois falava desde a usar o filtro solar, sombrinha e tudo mais, até o método PBL, então eu percebi que foi bem pensado assim, desde o básico até o máximo."

Apesar da maior parte dos comentários serem positivos, os estudantes sugeriram mudanças e melhorias ao manual: adição do horário máximo e mínimo de duração de um tutorial; nomes dos livros que mais são usados no $1^{\circ}$ ano do curso; alguns serviços que são oferecidos pela universidade aos discentes, como o Núcleo de Assistência Estudantil e a Pró-Reitoria de Extensão e Ações Comunitárias; informações sobre cursos de inglês oferecidos e de lugares, produtos e serviços com preços acessíveis. Também foi mencionado que mais imagens facilitariam a interação com o público-alvo e compreensão do material. Um aluno do grupo B sugeriu a inserção das rotas de ônibus da cidade para facilitar para os alunos provenientes de outros lugares do Brasil e outros, também do grupo $B$, sugeriram mais especificação nos critérios de avaliação dos tutoriais.

Fornecer informações corretas, de qualidade e apoiar o aluno no começo do curso é essencial para que o mesmo possa utilizar os benefícios a ele proporcionados pela 
universidade. Algumas informações a serem apresentadas: normas da instituição, como funciona o uso das bibliotecas, como obter documentos e acesso ao restaurante universitário, procedimentos de matrícula, e localização das unidades e serviços (TEIXEIRA et al., 2008).

Poucos não leram o manual ou não deram a devida atenção a ele, havendo apenas dois comentários negativos na discussão do grupo $A$, que inferiam falta de clareza no mesmo. Alguns discentes do grupo $B$ relataram que não conseguiram entender como funciona a avaliação dos módulos apenas com o manual, destacando essa parte como um critério que poderia ser melhorado.

\subsection{ACOLHIMENTO SATISFATÓRIO}

De forma geral, a apresentação do PBL foi vista de forma muito positiva pelos ingressantes de ambos os grupos, o acolhimento foi definido como satisfatório e a base da receptividade foi considerada muito boa:

"A parte do PBL, da Semana do Calouro foi a melhor parte!" (Acadêmica do grupo A).

Mas em si, foi muito boa, os veteranos fizeram de tudo pra acolher a gente, principalmente pessoal de fora com o manual do calouro por que eles realmente não tinham nenhuma noção, eu sou daqui mas tem muita gente que é de fora. E sim, eles se dedicaram mesmo na semana que eles tinham muita coisa pra fazer, pra estar com a gente de alguma forma, então apesar de alguns episódios que aconteceram, são coisas que a gente... faz uma crítica positiva pra melhorar, em si foi muito boa a semana. (Acadêmico do grupo B).

De acordo com Magalhães (2001), a boa receptividade é importante porque o ingresso na universidade marca o momento em que os acadêmicos vivenciarão mudanças constantes em um espaço repleto de novidades. O estudante vai se deparar com uma estrutura diferente daquela à qual estava habituado no ensino médio que muitas vezes causará insegurança. As vivências do primeiro ano marcam o curso, influenciado diretamente na continuidade e êxito acadêmico (PASCARELLA; TERENZINI, 2005; REASON; TERENZINI; DOMINGO, 2006). 
Os acadêmicos do grupo B mencionaram que o grupo criado em aplicativo de troca de mensagens, contendo calouros e veteranos e a experiência de apadrinhamento foram de grande ajuda, o que corrobora com o que Teixeira et al. (2008, p. 192) discorre em seu trabalho sobre adaptação à universidade:

O trote é visto como uma experiência que proporciona um entrosamento inicial com os demais colegas de turma e também de semestres posteriores, servindo como um "quebra-gelo". Esse momento descontraído pode ser ainda acompanhado de informações importantes, que auxiliarão na ambientação como dicas sobre professores e sobre o funcionamento da instituição.

A ausência de familiaridade com a universidade e de expectativas condizentes em relação à mesma pode contribuir para as questões de adequação, tanto pessoal quanto cognitivamente (BARDAGI, 2007; SANTOS; MELO-SILVA, 2003). Além disso, os eventos sociais que acontecem na integração com os demais estudantes (calouros e veteranos) e o próprio "trote" são fatores importantes na construção da identidade do indivíduo, processo que se dá a partir de conflitos e relações de poder (SIQUEIRA et al., 2012).

\subsection{CONSIDERAÇÕES GERAIS SOBRE A SECA: CRÍTICAS E SUGESTÕES}

Já que o feedback é usado de forma estruturada em cursos PBL para promover responsabilidade individual e grupal (TORRE; VAN DER VLEUTEN; DOLMANS, 2015), alguns alunos do grupo $A$ sugeriram que o feedback nesse caso referente à SECA seja sempre realizado, nos anos subsequentes: "Acho que seria muito interessante que a organização da SECA se preocupe em tentar saber o que os calouros acharam." (Acadêmica do grupo A). Parafraseando Azer (2005), o feedback é o café da manhã dos campeões.

Os espaços grandes de tempo entre as atividades da semana foram considerados como empecilho e motivo de desmotivação e frustação para os calouros do grupo $A$, uma vez que não tiveram uma semana propriamente dita no calendário acadêmico, e sim atividades espaçadas: 
Digamos que eles esperaram uns 4 meses pra ter a festa dos calouros, fazer a calourice de ir pra rua, que pelo menos no meu ponto de vista, pra mim eu não tava mais com aquele pique de fazer essas coisas sabe. (Acadêmico do grupo A).

“(...) Agora que chegou a outra turma no meio do ano, a gente não é mais OS calouros sabe?" (Acadêmica do grupo A).

Atribuíram esse fato à ausência de horário específico no calendário acadêmico para realização da semana do calouro e a falta de uma maior discussão por parte do colegiado e coordenação do curso que evidencie entre os docentes a importância de se haver uma semana específica para esse momento, sem demais atividades avaliativas para as turmas veteranas envolvidas no acolhimento. Importância esta evidenciada por Magalhães (2011, p.2), em seu trabalho sobre SECA na Universidade Estadual de Goiás:

[...] o desenvolvimento de atividades de integração, informativas, sociais e motivacionais nos primeiros dias letivos é fundamental para inserir os calouros no contexto acadêmico em que ele irá fazer parte e também contribui para uma introdução crítico reflexiva à vida universitária.

"Só que, infelizmente, ficou esse sentimento de incompleto, poxa eu queria ter tido meu trote, queria ter tido a festa logo após, quando eu entrei, queria que fosse tudo numa semana só." (Acadêmico do Grupo A).

Foram sugeridas algumas alternativas para essa questão, como a liberação dos veteranos durante essa semana e a ocupação um turno só com atividades, buscando a flexibilização dos horários em um acordo com a coordenação, além de procurar saber o horário com antecedência, tanto de calouros quanto de veteranos. Esse tempo para realização da integração na SECA é necessário, pois o ambiente universitário provoca uma mudança radical na vida do jovem, trazendo circunstâncias desafiadoras relacionadas ao curso da vida, que por sua vez necessitam de adaptação e de novas respostas (GOTTLIEB; STILL; NEWBY-CLARK, 2007). 
Para além de atributos na grandeza, nos objetivos ou critérios de seleção da instituição, a ambiência e os aspectos culturais da universidade influenciam mais evolução e desempenho acadêmico do estudante (BERGER, 2000).

"A gente ouviu relato, eu ouvi relato, até de que alguns alunos faltando em aula pra tá lá com a gente." (Acadêmico do Grupo B).

Eu pediria que a semana do calouro fosse realmente uma semana que o veterano tivesse uma flexibilidade nos horários, uma redução de conferências e outras coisas, não sei... mudar o horário da tutoria pra flexibilizar... (...)E que os próprios calouros não tivessem atividades, atividades valendo nota, presença, por que gente, aí você cai aqui de paraquedas, a maioria das pessoas da nossa turma são de fora: você vai comprar móveis, você vai receber seus pais que tão vindo pra cerimônia do jaleco, não é assim, você não está bem não, tem gente que tá no hotel, que se perde, perde o ônibus, perde não sei o quê. (Acadêmica do Grupo B).

Acho que os alunos tem que entrar em contato com a coordenação, pra eles conversarem, até mesmo pelo que eu falei da questão do horário, que eles não sabiam. É entrar em contato com a coordenação e olha: 'essa semana eles vão ter aula, não vão ter'. Eles tem que entrar em um acordo aí pra ver se liberam, se... pros próximos calouros não ficarem perdidos... (Acadêmico do Grupo B).

Lassance e Gocks (1995) referem como ponto importante para adesão favorável ao curso superior a aproximação ao grupo social que ali se encontra. Diniz e Almeida (2006) encontraram que as relações interpessoais eram mais relevantes para a acomodação do indivíduo no primeiro período do que as responsabilidades acarretadas, que por vez sua ganhavam mais notoriedade no segundo período da formação.

O grupo B também sugeriu que em vez de palestras sobre "como estudar", fossem realizadas palestras de "como estudar para o método PBL", podendo até mesmo serem ministradas pelos próprios alunos, já que eles vivenciam continuamente o PBL, ou por professores formados por essa metodologia.

Sim sim, eu sei que tem 1 ou 2 professores, não sei, que estudaram pelo método PBL, escutei por alto... Então...gostaria sim de escutar desses professores, como é que é, se existe metodologia de estudo em casa, 
para aquilo que eu vi, que eu vi dentro da faculdade, do curso né. Então, se existe um método de estudo para dentro de casa, organização de estudo... (...) Mas se não existe, se o mais didático, mais apropriado é aprender com os veteranos, como é que eles estão estudando, como é que eles se adaptaram, adaptaram a rotina deles de estudo, eu prefiro ouvir daquilo que dá pra ser digerido. (Acadêmica do grupo B).

Como observado acima, os alunos trouxeram em suas colocações alternativas para os supostos problemas que enfrentaram na semana do calouro, o que é excelente uma vez que almejam contribuir positivamente para a construção de um acolhimento melhor para todos. Tais considerações corroboram com o objetivo do trabalho e com a ênfase que o mesmo presta à importância da primeira semana em um ambiente universitário ser satisfatória.

\section{CONSIDERAÇÕES FINAIS}

De forma geral, a maior parte dos estudantes de ambos os grupos julgaram a Semana do Calouro como positiva, elogiaram a receptividade e enfatizaram a dedicação dos veteranos para que os eventos acontecessem da forma planejada. A apresentação do PBL também foi avaliada como eficiente por ambos os grupos, tendo sido levantada como sugestão a manutenção da prática de feedback em todas as turmas ingressantes.

Os grupos relataram impacto favorável do tutorial simulado na adaptação inicial, enfatizando que a sessão simulada proporcionou um embasamento no que se refere às regras e à dinâmica de funcionamento de um tutorial real, mas que o aprendizado total se deu mesmo com tempo e prática. Mesmo alunos que não compareceram à sessão ouviram comentários benéficos da experiência e dicas que lhes ajudaram no início do processo.

Ambos os grupos relataram persistência de dificuldades relacionadas à adaptação ao novo método, entre elas a dificuldade de executar a função de secretário e de estudar da maneira correta para o tutorial. Os acadêmicos não se sentiriam seguros em explicar o método a um leigo somente com a simulação. 
O manual do calouro teve boa recepção, sendo avaliado como "muito bom" pelos ingressantes. Foram ainda sugeridas melhorias no manual, como a complementação de critérios específicos do tutorial, informações extras sobre a faculdades e a adição de outros serviços da cidade. Das críticas ao manual são citadas falta de clareza e falta de esclarecimento quando ao funcionamento avaliativo dos módulos. Houve pequenos ajustes no documento apresentado à segunda turma, considerando-se análise prévia do feedback dos alunos da primeira turma. Tal fato pode indicar um viés para a presente pesquisa.

A falta de um espaço de tempo adequado para a semana do calouro foi considerada um empecilho, pois o calendário acadêmico não apresenta um momento dedicado a recepção dos calouros. Quanto a isso foram sugeridas mudanças para melhor adequar a realização dessas atividades.

Vale ainda mencionar como dificuldade para o desenvolvimento do presente trabalho a ausência de outros trabalhos com o mesmo desenho e com a temática semelhante. No Brasil, existem poucos estudos recentes sobre a adaptação à universidade (TEIXEIRA et al., 2008), sendo, portanto, escassos os artigos que pudessem construir a fundamentação teórica e a discussão de resultados. Os poucos que forma encontrados eram muitas vezes relacionados ao tema geral "educação médica" e não diretamente relacionados ao evento de recepção de alunos na faculdade de medicina.

Espera-se com esse trabalho fornecer subsídios para que os pontos positivos destacados sejam mantidos e aprimorados na introdução da metodologia ativa PBL aos novos discentes, ao passo que os aspectos negativos sejam reavaliados e modificados para que os próximos alunos dos anos que virão sejam recebidos da forma mais adequada e esclarecedora possível.

\section{REFERÊNCIAS}

AZER, Samy A. Challenges facing PBL tutors: 12 tips for successful group facilitation. Medical teacher, 27, 8, 676-681, 2005. 
BARDAGI, Marúcia Patta. Evasão e comportamento vocacional de universitários: estudos sobre o desenvolvimento de carreira na graduação. Universidade Federal do Rio Grande do Sul, Porto Alegre, Tese de doutorado não publicada, 2007. Disponível em: http://livros01.livrosgratis.com.br/cp047876.pdf. Acesso em 23 dez 2019.

BARDIN, Laurence. Análise de conteúdo (Edição revista e atualizada). Lisboa: Edições, 2009.

BRASIL, Tatiana Lima. RESILIÊNCIA INTEGRAL: Um caminho de possibilidades para formação humana de futuros docentes. Orientador: Prof. Dr. Aurino Lima Ferreira. 2019. 332 f. Tese (Doutorado em Educação) - Universidade Federal de Pernambuco, Recife, PE, 2019. Disponível em: https://repositorio.ufpe.br/bitstream/123456789/34274/1/TESE\%20Tatiana\%20Lima \%20Brasil.pdf. Acesso em: 11 jun. 2020.

BELFOR, Jiulyanne Andrade. SENA, luri Silva. SILVA, Dyone Karla Barbosa Da. LOPES, Bruno Rafael Da Silva. JÚNIOR, Mário Koga. SANTOS, Bráulio Érison França Dos. Competências pedagógicas docentes sob a percepção de alunos de medicina de universidade da Amazônia brasileira. Ciênc. Saúde Coletiva, 23, 73-82, 2018.

BELLODI, Patrícia Lacerda. O programa tutores e a integração dos calouros na FMUSP. Rev Bras Educ Med, 28, 3, 204-214, 2004.

BERGER, Joseph. Organizational behavior at colleges and student outcomes: A new perspective on college impact. Rev High Educ, 23, 177-198, 2000.

DE CAMPOS, Leonara Raddai Gunther. RIBEIRO Mara Regina Rosa, DEPES, Valéria Binato Santili. Autonomia do graduando em enfermagem na (re) construção do conhecimento mediado pela aprendizagem baseada em problemas. Rev Bras Enferm, 67, 5, 818-824, 2014.

DE CAMARGO RIBEIRO, Luis Roberto. Aprendizagem baseada em problemas (PBL) na educação em engenharia. Revista de Ensino de Engenharia, 27, 2, 23-32, 2008. 
DECI, Edward L. RYAN, Richard M. Handbook of self-determination theory research. Rochester, NY: The University of Rochester Press, 2002.

DE OLIVEIRA, Gabriella Santos. ROCHA, Carina Araújo. SANTOS, Bráulio Érison França dos. SENA, luri Silva. FAVARO, Leandro. GUERREIRO, Mateus Coelho. Prevalência e fatores associados à depressão em estudantes de medicina da Universidade Federal do Amapá. Rev Med Saude Brasília, 5, 3, 2017.

DINIZ, Antônio M. ALMEIDA, Leandro S. Adaptação à Universidade em estudantes do primeiro ano: Estudo diacrónico da interacção entre o relacionamento com pares, o bem-estar pessoal e o equilíbrio emocional. Anál Psicol, 24, 1, 29-38, 2006.

FERNANDES, Artur José Silva, MELLO, Maria Helena Campos Soares de, MELLO, João Carlos Correia Baptista Soares de. O Ensino de Cálculo1: A Evolução na UFF. In: VII Encontro de Ensino Engenharia. 2001 [Acessado em 06 jun 2019] 1(1) [cerca de 8 p.]. Disponível em: http://www.dee.ufrj.br/VIIEEE/VIIEncontro/arquivos/19.pdf.

FRANCO, Camila Ament Giuliani dos Santos. CUBAS, Marcia Regina. FRANCO, Renato Soleiman. Currículo de medicina e as competências propostas pelas diretrizes curriculares. Rev Bras Educ Med, 38, 2, 221-230, 2014.

GARCIA, I. Vulnerabilidade e resiliência. Adolescência Latino-Americana. 2:128-130, 2001.

GOTTLIEB, Benjamin H. STILL, Eva. NEWBY-CLARK, lan R. Types and precipitants of growth and decline in emerging adulthood. J Adolesc Res, 22, 132-155, 2007.

IERVOLINO, Solange Abrocesi. PELICIONI, Maria Cecilia Focesi. A utilização do grupo focal como metodologia qualitativa na promoção da saúde. Rev Esc Enf USP, 35, 2, 115-121, 2001.

LASSANCE, M.C.P. GOCKS, A. A formação da identidade profissional em universitários: A questão da prática. Anais do Simpósio Brasileiro de Orientação Vocacional e Ocupacional, São Paulo: ABOP, 2, 65-70, 1995. 
MAGALHÃES, Ana Paula A.S. Semana do calouro do curso de matemática da Unucet. Universidade Estadual de Goiás, 1, 1, 2011. Disponível em: https://serex2012.proec.ufg.br/up/399/o/ANA_PAULA_A_S_MAGALHAES.pdf. Acesso em 06 jun 2019.

MAMEDE, Silva. Aprendizagem baseada em problemas: anatomia de uma nova abordagem educacional. Fortaleza: Hucitec, 2001, p. 25-48

NOVAK, Joseph D. GOWIN, D Bob. Learning how to learn. Cambridge: Cambridge University Press, 1984.

PASCARELLA, Ernest T. TERENZINI, Patrick T. Organizadores. How college affects students: A third decade of research. San Francisco: Jossey-Bass, 2005.

REASON, Robert D. TERENZINI, Patrick T. DOMINGO, Robert J. First things first: Developing academic competence in the first year of college. Res High Educ, 47, 149175, 2006.

RODRIGUES, Jéssica de Alcântara. ROCHA, Luanna dos Santas. ANJOS, Danielly Santos dos. CAVALCANTE, Leila Pacheco Ferreira. ROZENDO, Célia Alves. Tendências pedagógicas: conflitos, desafios e perspectiva de docentes de enfermagem. Rev Bra Educ Med, Maceió, 37, 3, 333-349, 2013.

RYAN, Richard M. DECI, Edward L. Self-determination theory and the facilitation of intrinsic motivation, social development, and well-being. Am Psychol, 55, 1, 68, 2000.

SANTOS, M. A. MELO-SILVA, L .L. "Será que era isso o que eu queria?" A formação acadêmica em psicologia na perspectiva do aluno. Em Melo-Silva LL, Santos MA, Simão JT, Avi MC, organizadores. Arquitetura de uma ocupação - orientação profissional: Teoria e técnica. São Paulo: Vetor, 1, 387-406, 2003.

SANTOS, Wilton Silva. Organização Curricular Baseada em Competência na Educação Médica. Rev Bra Educ Med, Rio de Janeiro, 35, 1, 86-92, 2011. 
SIQUEIRA, Vera Helena Ferraz de et al. Construções identitárias de estudantes de farmácia no trote universitário: questões de gênero e sexualidade. Pro-Posições, v. 23, n. 2, p. 145-159, 2012.

TEIXEIRA, Marco Antônio Pereira. DIAS, Ana Cristina Garcia. WOTTRICH, Shana Hastenpflug. OLIVEIRA, Adriano Machado. Adaptação à universidade em jovens calouros. Psicol Esc Educ, 12, 1, 185-202, 2008.

TEN CATE, Olle Th J. KUSURKAR, Rashmi A. WILLIAMS, Geoffrey C. How selfdetermination theory can assist our understanding of the teaching and learning processes in medical education. AMEE guide No. 59. Medical teacher, 33, 12, 961973, 2011.

TOLEDO JÚNIOR, Antônio Carlos de Castro. IBIAPINA, Cássio da Cunha, LOPES Simone Cláudia Facuri. RODRIGUES, Ana Cristina Persichini, SOARES, Sílvia Mamede Studart. Aprendizagem baseada em problemas: uma nova referência para a construção do currículo médico. Rev Med Minas Gerais, 18, 2, 123-131, 2008.

TORRE, Dario M. VAN DER VLEUTEN, Cees. DOLMANS, Diana. Theoretical perspectives and applications of group learning in PBL. Medical teacher, 38, 2, 189195, 2015

VASCONCELOS, Paulo Denisar. A violência no escárnio do trote tradicional: Um estudo filosófico em antropologia cultural. Santa Maria: Imprensa Universitária, p. 1415, 1993.

WAGNER, Adriana. Como se perpetua a família? A transmissão dos modelos familiares. Porto Alegre: EDIPUCRS, 2014.

WEINTRAUB, Miriam. HAWLITSCHEK, Philippe. JOÃO, Sílvia Maria Amado. Jogo educacional sobre avaliação em fisioterapia: uma nova abordagem acadêmica. Fisioter Pesqui, 18, 3, 280-286, 2011. 
ZAJACOVA, Anna. LYNCH, Scott M., ESPENSHADE, Tomas J. Self-efficacy, stress, and academic success in college. Res High Educ, 46, 677-706, 2005.

Enviado: Agosto, 2020.

Aprovado: Janeiro, 2021. 